\title{
The Disease Burden of Patients with Allergic Rhinitis from a Hospital Surveillance in Beijing
}

\author{
Fengying Zhang ${ }^{1,2,3, *}$, Chengjing Nie ${ }^{4}$, Li Wang ${ }^{2,3}$, Mark Rosenberg ${ }^{5}$, Jin Xu ${ }^{6}$, \\ Thomas Krafft ${ }^{2,3}$ and Wuyi Wang ${ }^{2, *}$ \\ 1 China National Environmental Monitoring Center, Beijing 100012, China \\ 2 Institute of Geographic Sciences and Natural Resources Research, Chinese Academy of Sciences, \\ Beijing 100101, China; li.wang@maastrichtuniversity.nl (L.W.); thomas.krafft@maastrichtuniversity.nl (T.K.) \\ 3 Department of International Health, Faculty of health, Medicine and Life Sciences, Maastricht University, \\ 6200 MD Maastricht, The Netherlands \\ 4 School of Public Administration and Policy, Hebei University of Economics and Business, \\ Shijiazhuang 050061, China; chengjingnie@163.com \\ 5 Department of Geography, Queen's University, Kingston, ON K7L 3N6, Canada; \\ mark.rosenberg@queensu.ca \\ 6 Department of Otolaryngology-Head and Neck Surgery, Beijing Hospital, Ministry of Public Health, \\ Beijing 100730, China; xujin139@163.com \\ * Correspondence: zhangfy@cnemc.cn (F.Z.); wangwy@igsnrr.ac.cn (W.W.)
}

Academic Editor: Marc A. Rosen

Received: 21 November 2016; Accepted: 9 March 2017; Published: 14 March 2017

\begin{abstract}
Background: The aims of this study are to estimate the disease burden of allergic rhinitis (AR) patients and examine various underlying issues related to the symptoms and services of adult AR patients. Methods: Beijing hospital was picked as the surveillance area, and self-report questionnaires from the AR patients and data from medical examinations by specialists of otolaryngology were collected. The burden of patients with AR was evaluated by the combined results from patient-questionnaires and specialist examination reports. Results: AR imposed a substantial burden on patients regarding everyday life limitations and work performance; AR affected patients' noses, ears, throats, and eyes in various ways. The basic daily average medicine cost was $10 \mathrm{RMB}$ for each patient, and the cost for an outpatient in the hospital was $10 \mathrm{RMB}$ for a basic nasal examination and more than $200 \mathrm{RMB}$ if the patient needed further physical examinations. Conclusions: AR imposed burdens on everyday activities and work performance; the patients needed to wait a long time before being diagnosed, and the costs of diagnosis and treatment imposed economic burden on patients.
\end{abstract}

Keywords: allergic rhinitis; disease burden; outpatients; Beijing

\section{Introduction}

Allergic rhinitis (AR) is a complex disease involving several associated disorders and is a risk factor for asthma [1-5]. It affected $10 \%$ to $30 \%$ of adults and $40 \%$ of children worldwide, 400 million people in the world suffer from AR [1,6]. In recent years, the prevalence of AR has increased annually throughout the world, seriously affecting the quality of life of children, and creating a serious burden to patients, family, and society [4,7-9].

It was proposed that severe chronic upper-airway disease arises when rhinitis is not controlled with adequate pharmacotherapy. This disorder can affect $20 \%$ of people with rhinitis, with concomitant severe effects on quality of life, work, and school performance $[4,10]$. Subjects with AR have an increased risk of developing asthma and may constitute a suitable population for secondary intervention to interrupt the "allergic march" [11]. 
Hidden direct costs include the treatment of comorbid asthma, chronic sinusitis, otitis media, upper respiratory infection, and nasal polyposis [12]. AR usually accompanies other syndromes or diseases, including acute or chronic rhinosinusitis, nasal polyps, otitis media with effusion, and hearing impairments [13]. Nasal congestion is associated with sleep-disordered breathing, which can have a profound effect on mental health, including increased psychiatric disorders, depression, and anxiety [12]. Furthermore, sleep-disordered breathing in childhood and adolescence is associated with increased disorders of learning performance, behavior, and attention [1]. In the United States, AR results in 3.5 million lost workdays and 2 million lost schooldays annually [12].

AR can result in a significant public health burden to patients, such as lower quality of life, detrimental effects on workplace and school performance, limited social activities, medication usage, and increased comorbidity for other health conditions including asthma, hypertension, sinusitis, and otitis media [3,14-16]. Allergic conditions require potentially complex and expensive therapeutic intervention and are thus also associated with both direct and indirect cost, such as missed school and work days $[7,10,17]$. Such conditions constitute a challenge for both public health organizations and healthcare providers $[15,18]$.

People with allergies are being badly let down, as there are inadequate facilities, resources, and specialists to investigate, manage, and treat them in all countries [17]. This situation is even worse in China where only a few studies have been conducted on AR [19]. A self-report study conducted in China showed that the prevalence rates of AR were $14.46 \%, 20.42 \%$, and $7.83 \%$ in Beijing, Chongqing, and Guangzhou, respectively. About $10.73 \%$ of the AR patients suffered from asthma [20].

The perspectives of patients and specialists on the burden of disease for AR have been described for the United States [21,22], Europe [23], UK [24], and other countries [7,25]. Fewer studies focused on the AR burden on people in China, and research related to adult AR patients was particularly rare because of the data limitation $[6,19,26]$.

Air pollution has proved to be positively associated with AR [19,26,27], with the exacerbation of air pollution in China, it is of importance to evaluate the burden of the AR to provide precaution suggestions.

In order to explore the $\mathrm{AR}$ burden from patient and specialist perspectives, using patient-questionnaires and specialist examination reports, this study estimated the monetized and non-monetized burden of AR on adult patients in Beijing.

\section{Methodology}

\subsection{Study Populations and Definitions}

Beijing Hospital and its catchment were included as our study area. The hospital is a Class-Three, Grade A level hospital, located in the Dong Cheng District in Central Beijing, providing large-scale comprehensive integrated health services including medical treatment, teaching and education, scientific research, and disease prevention. The hospital is open to the general public. The number of children and adolescents consulting Beijing Hospital as outpatients is relatively small, because they are usually treated at specialized pediatric clinics. This age group is therefore underrepresented in the study.

Daily numbers of persons consulting general practitioners for AR for the period between 19 March 2009 and 18 March 2010 (study period) were obtained from the Department of Otolaryngology-Head and Neck Surgery in Beijing Hospital. All outpatients diagnosed by specialists from the Department of Otolaryngology of Beijing hospital, during 19 March 2009 to 18 March 2010 were included in the study.

The patients were diagnosed with rhinitis by evaluating patients' medical history, through a standardized questionnaire and a test. AR was defined as having symptoms of sneezing, or a running, itchy, or blocked nose when the patient did not have a cold or flu. Only one visit per individual 
patient per day was included in the study. Subsequent follow-up visits that occurred after the initial consultation were not included in the count.

This study was approved by the Ethics Review Board of Beijing Hospital, Ministry of Public Health, and the Ethics Review Board of Institute of Geographic Sciences and Natural Resources Research, Chinese Academy of Sciences. All patients gave written consent to participate in the study.

\subsection{Methodology}

In this study, we assessed the AR burden of patients in two ways. First, the patients' physical examination results from the specialist and the self-report from the patients were combined to study the non-financial burden of the patient. Second, the basic economic cost for patients incurred for disease control or cure and the fee for the patient's physical examination in the hospital was included to estimate the financial burden of the patients.

\subsubsection{Examination Reports from Specialists}

When the specialists in the outpatient clinics conducted examinations of AR patients, a standardized examination report form was filled out by the specialists or research nurses for each patient. Specialists recorded patient characteristics, diagnostic history, such as current or past diagnostic investigations for AR, current symptoms and their severity, any other frequent symptoms (not present at the time of the consultation), common triggers, comorbid conditions (based on a current or past clinical history of diagnosed respiratory and/or allergic conditions), current drug treatments, and decisions to operate.

\subsubsection{Questionnaire from Patients}

The patients who were diagnosed with AR were invited to fill out a patient questionnaire. The questionnaire covered personal information (career, gender, age, etc.), comorbidities, symptom of rhinitis (wheezing or cough, eczema, burning or itching of the eyes, etc.), and any effects on quality of life.

\subsection{Questionnaire Analysis}

All questionnaires and specialists examination report data were coded and entered into a programmed database by two persons independently. The data were checked for out-of-range values and logical mistakes. The perceptions of patients and specialists regarding the symptoms of AR and its severity and impact on general well-being and everyday life were assessed.

For the definition on AR severity, we followed the Allergic Rhinitis and its Impact on Asthma (ARIA) guidelines. The ARIA guidelines for classification and treatment of AR have led to the definition of allergic nasal disease as mild or moderate-to-severe [2]. Patient with mild AR was defined as patients having normal sleep, daily activities, work and school performance, and no troublesome symptoms. Moderate-to-severe severity patients were defined as patients who have one or more of the following symptoms: abnormal sleep, impairment of daily activities/sport and leisure, difficulties caused at school or work, and other troublesome symptoms $[2,10]$.

In order to estimate the economic loss to patients, the cost of daily medicine use and outpatient fees of the patients were calculated and analyzed.

\subsection{Quality Control}

Uniform protocols and questionnaires were used for this study. All interviewers (specialists or research nurses) and all analysts of the specialist's examination report were carefully trained before the study. Results of the questionnaires and the specialist's examination reports were sent every month to the IGSNRR (Institute of Geographic Sciences and Natural Resources Research, CAS), where the data 
were entered and analyzed. Each completed questionnaire and specialist's examination report was verified by the center supervisor and the results were double-checked by the principal investigator.

\section{Results}

\subsection{Characteristics of Outpatients Reporting AR}

During our study period of 12 months (March 2009 to March 2010), a total number of 31,829 outpatients attended the Department of Otolaryngology-Head and Neck Surgery at Beijing Hospital. Of the total number, 1506 (4.7\%) of these were diagnosed with AR. The gender distribution was about 1:1 [19].

\subsection{Reports from AR Patients}

\subsubsection{Self-Reported Symptoms}

We divided the AR symptoms into ten categories, headache, itchy eyes, tears, itchy ears, itchy throat, cough, feel suffocated, itchy skin, rash, and asthma. In the sample, patients reported the following: headaches $(25.5 \%)$, itchy eyes $(52.6 \%)$, tears $(49.0 \%)$, itchy ears $(24.4 \%)$, itchy throats $(30.4 \%)$, coughs $(22.7 \%)$, difficulty breathing $(17.8 \%)$, itchy skin $(8.5 \%)$, rash $(8.5 \%)$, and asthma $(5.5 \%)$. In terms of the number of symptoms, some patients reported just one symptom (24.8\%), some two symptoms $(30.3 \%)$, and some three or more symptoms (43.3\%).

\subsubsection{Influence on Quality of Life}

For evaluating the influence on quality of life, we chose six outcomes of AR: sleep disturbances, daily life limitations, sports limitations, altered work, learning impairments, and nuisance symptoms.

The following outcomes were reported by patients: sleep disturbances $(53.8 \%)$, daily life limitations $(51.3 \%)$, sports limitations $(9.5 \%)$, altered work $(31.7 \%)$, learning impairments $(5.3 \%)$, and nuisance symptoms (8.3\%). In terms of the number of outcomes of AR, some patients reported one outcome (59.1\%), some two outcomes $(24.3 \%)$, and some three or more outcomes $(16.6 \%)$.

\subsubsection{Comorbidities}

In the patients' self-report questionnaire, we also collected information on comorbidities of the AR patients. Asthma, dermatitis, eczema, conjunctivitis, catarrhal otitis media, allergic sphagitis, nasal polyp, and sinusitis were taken into consideration. The results showed that $47.7 \%$ AR patients have comorbidities: asthma $(11.1 \%)$, dermatitis $(11.4 \%)$, eczema $(9.3 \%)$, conjunctivitis $(15.1 \%)$, catarrhal otitis $(<1 \%)$, allergic sphagitis $(<1 \%)$, nasal polyp $(2.0 \%)$, and sinusitis $(10.9 \%)$. Most patients have one kind of comorbidity $(72.2 \%)$, and only a few patients have two or more $(27.8 \%)$.

\subsubsection{Self-Reported Severity}

Table 1 summarized the results of self-report from AR patients. Based on the ARIA guidelines on classification and treatment of AR, we combined the results from the patients' questionnaires. In this study, all of the patients have at least one troublesome symptom that is listed on the ARIA guidelines, which means that all of the AR patients who consulted with specialists had moderate-to-severe AR. 
Table 1. Self-reports from allergic rhinitis (AR) patients.

\begin{tabular}{ccc}
\hline Self-Reported Symptoms & Influence on Quality of Life & Comorbidities \\
\hline headaches $(25.5 \%)$ & sleep disturbances $(53.8 \%)$ & asthma $(11.1 \%)$ \\
itchy eyes $(52.6 \%)$ & daily life limitations $(51.3 \%)$ & dermatitis $(11.4 \%)$ \\
tears $(49.0 \%)$ & sports limitations $(9.5 \%)$ & eczema $(9.3 \%)$ \\
itchy ears $(24.4 \%)$ & altered work $(31.7 \%)$ & conjunctivitis $(15.1 \%)$ \\
itchy throats $(30.4 \%)$ & learning impairments $(5.3 \%)$ & catarrhal otitis $(<1 \%)$ \\
coughs $(22.7 \%)$ & nuisance symptoms $(8.3 \%)$ & allergic sphagitis $(<1 \%)$ \\
difficulty breathing $(17.8 \%)$ & & nasal polyp $(2.0 \%)$ \\
itchy skin $(8.5 \%)$ & & sinusitis $(10.9 \%)$ \\
rash $(8.5 \%)$ & & \\
asthma $(5.5 \%)$ & & \\
\hline
\end{tabular}

\subsection{Symptomatology}

The specialists' examinations included the examination of the following organs of the AR patients: nose, ears, throat, and eyes.

\subsubsection{Direct Symptoms of AR}

We divided the direct symptoms of AR into sneezing, clear nasal discharge flow, nasal congestion, and nasal itching. The following symptoms were found among the patients: sneezing (91.5\%), clear nasal discharge flow $(86.4 \%)$, nasal congestion $(68.4 \%)$, and nasal itching $(68.1 \%)$. In terms of frequency of symptoms, the percentages were as follows: one symptom $(4.3 \%)$, two symptoms $(17.5 \%)$, three symptoms (32.5\%), and all four symptoms (45.7\%).

\subsubsection{Inferior Turbinate Mucosa}

For the body examination of inferior turbinate mucosa, we used eight symptoms to classify the results: paleness, edema, watery snot, pinkness, rosiness, congestion, dull-redness, and hypertrophy. The patient results showed pale inferior turbinate mucosa $(55.9 \%)$, edema $(72.8 \%)$, watery snot in the inferior turbinate mucosa $(36.6 \%)$, pink inferior turbinate mucosa $(6.9 \%)$, rosy inferior turbinate mucosa $(2.4 \%)$, dull-red inferior turbinate mucosa $(2.4 \%)$, and hypertrophy in inferior turbinate mucosa $(11.1 \%)$. The frequency of symptoms in inferior turbinate mucosa reported was as follows: one symptom $(23.3 \%)$, two symptoms $(42.3 \%)$, three symptoms (32.7\%) and four or more symptoms $(1.7 \%)$.

\subsubsection{Middle Turbinate}

A very important effect of AR is on the nasal middle turbinate. Examinations for this condition showed $49.7 \%$ had visible nasal middle turbinate, $49.8 \%$ had nasal invisible middle turbinate at two sides, and $0.5 \%$ of the patients had invisible nasal middle turbinate at one side and visible nasal middle turbinate at the other side.

\subsubsection{Nasal Middle Tract}

We classify the results of nasal middle tract into three types: visible, invisible, and having secretions inside. The percentage of patients by type was as follows: visible nasal middle tract $(39.6 \%)$, invisible nasal middle tract $(51.7 \%)$, secretions inside $(2.0 \%)$, visible nasal middle tract and secretions inside $(1.4 \%)$, and invisible nasal middle tract and secretions inside $(5.3 \%)$.

\subsubsection{Nasal Septum}

We define the nasal septum into three categories, normal, mild deviated, and moderate to severe deviated nasal septum. The percentage of patients by type was as follows: normal nasal septum $(45.5 \%)$, mild deviated septum $(37.8 \%)$, and moderate to severe deviated nasal septum $(16.7 \%)$. 


\subsubsection{Ears, Throats, and Eyes}

The examination of ears focuses on two conditions: status of the skin in the ear canal (congestion, moisture, chap, and desquamation) and the eardrum (congestion and moisture). For status of the ear canal skin, the results were as follows: congestion (8\%), moisture (9.7\%), chap $(9.7 \%)$, and desquamation $(77.9 \%)$. For status of the eardrum, the results were as follows: congestion $(2.7 \%)$, and moisture $(3.5 \%)$. The throat examination results were classified as congestion (95.5\%), dryness (1\%), swelling $(1.4 \%)$, and normal throat $(2.1 \%)$. The results of eye checks were classified as follows: congestion $(31.2 \%)$, eye edema $(2.6 \%)$, watery eyes $(42.5 \%)$, and normal eyes (23.7\%). In the sample, $17.5 \%$ patients had two eye symptoms, and $6.2 \%$ patients had three eye symptoms.

\subsubsection{Disease Severity of the Patient}

Table 2 summarizes the results of the specialists' examination. Based on the results from the specialists' examinations, for the direct symptoms of AR (sneezing, clear nasal discharge flow, nasal congestion, and nasal itching), $17.5 \%$ of patients suffered two symptoms, $32.5 \%$ of the patients suffered three symptoms, and nearly half of the AR patients (45.7\%) suffered all four of the symptoms. The patients' inferior turbinate mucosa, nasal middle turbinate, nasal middle tract, nasal septum, ears, throat, and eyes were all affected in some way. This means that all of the AR patients who consulted specialists in Department of Otolaryngology-Head and Neck Surgery of Beijing hospital had a moderate to severe AR.

Table 2. Results from specialists' examination.

\begin{tabular}{|c|c|c|c|c|}
\hline Direct Symptoms & Inferior Turbinate Mucosa & Middle Turbinate & \multicolumn{2}{|c|}{ Nasal Middle Tract } \\
\hline sneezing $(91.5 \%)$ & paleness $(55.9 \%)$ & visible $(49.7 \%)$ & \multicolumn{2}{|c|}{ visible $(39.6 \%)$} \\
\hline \multirow{2}{*}{$\begin{array}{l}\text { clear nasal discharge } \\
\text { flow }(86.4 \%)\end{array}$} & edema $(72.8 \%)$ & invisible $(49.8 \%)$ & \multicolumn{2}{|c|}{ invisible (51.7\%) } \\
\hline & watery snot $(36.6 \%)$ & \multirow{5}{*}{$\begin{array}{l}\text { invisible at one } \\
\text { side and visible at } \\
\text { the other side } \\
(0.5 \%)\end{array}$} & \multicolumn{2}{|c|}{ secretions inside $(2.0 \%)$} \\
\hline \multirow{2}{*}{$\begin{array}{c}\text { nasal congestion } \\
(68.4 \%)\end{array}$} & pinkness $(6.9 \%)$ & & \multicolumn{2}{|c|}{ visible $(1.4 \%)$} \\
\hline & Rosiness $(2.4 \%)$ & & \multirow{2}{*}{\multicolumn{2}{|c|}{ invisible and secretions inside (5.3\%) }} \\
\hline \multirow{2}{*}{ nasal itching $(68.1 \%)$} & dull-redness (2.4\%) & & & \\
\hline & hypertrophy (11.1\%) & & & \\
\hline Nasal Septum & Ear Canal Skin & Ear Drum & Throats & Eyes \\
\hline normal (45.5\%) & congestion $(8 \%)$ & congestion $(2.7 \%)$ & congestion $(95.5 \%)$ & congestion $(31.2 \%)$ \\
\hline mild deviated $(37.8 \%)$ & moisture $(9.7 \%)$ & moisture $(3.5 \%)$ & dryness $(1 \%)$ & eye edema $(2.6 \%)$ \\
\hline \multirow{2}{*}{$\begin{array}{c}\text { moderate to severe } \\
\text { deviated }(16.7 \%)\end{array}$} & chap $(9.7 \%)$ & & swelling $(1.4 \%)$ & watery eyes $(42.5 \%)$ \\
\hline & desquamation (77.9\%) & & normal throat $(2.1 \%)$ & normal eyes $(23.7 \%)$ \\
\hline
\end{tabular}

\subsection{Other Losses of Patients}

Figure 1 shows the standard procedure of an outpatient visit. Besides the burden mentioned in Sections 3.2 and 3.3, the AR patients also had other losses, such as the traffic fee, payment for diagnosis or medicine, the time spent on traffic and waiting for diagnosis in hospital, and so on.

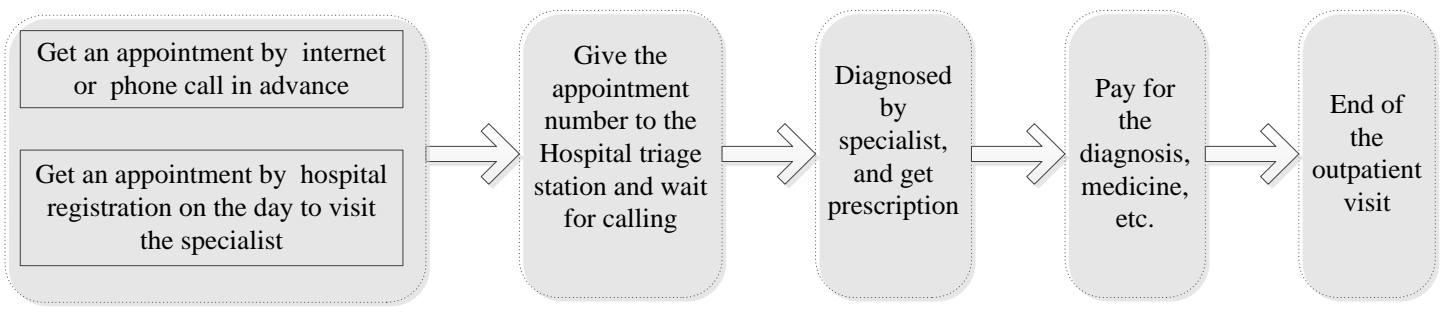

Figure 1. Outpatient procedure of visiting an AR specialist. 
It was difficult to calculate the exactly time every patient spent on the road, so here we just considered the average time the patients spent in the hospital. The Department of Otolaryngology-Head and Neck Surgery of Beijing Hospital has nine specialists in total. The average amount of outpatient visits in the Department of Otolaryngology-Head and Neck Surgery was 273 per day, so each specialist had 30 patients per day on average. Most people liked to visit the specialist in morning, so we split the number into two parts, 18 in the morning and 12 in the afternoon. The average diagnosis time was $5 \mathrm{~min}$ for each patient, which refers only to the time spent waiting for a diagnosis; Patient No. 1 did not need to wait, Patient No. 2 needed to wait 5 min, Patient No. 3 needed to wait $10 \mathrm{~min}$, Patient No.18 needed to wait no less than $85 \mathrm{~min}$ in the morning, and Patient No. 12 needed to wait at least $55 \mathrm{~min}$ in the afternoon.

In terms of economic loss, due to a lack of other information, in this study, we only considered daily economic burden and economic loss for each outpatient visit. We divided economics cost into two parts: daily-used medicine costs and costs from physical examinations in the hospital.

Most of the patients needed to take a tablet and use a nasal spray every day during the course of their illness. The tablet costed about 5 RMB. The nasal spray was 100 RMB per bottle and can last for 15-20 days, so the daily cost for nasal spray was about 5 RMB. Most patients used both the tablets and the nasal spray, and many patients took more than one kind of tablet when they had serious symptoms. So the basic daily average medicine cost for a patient was 10 RMB.

Each step in seeing a specialist had a cost associated with it. First, a patient pays 5 RMB or more to register each time, and the equipment for a basic nasal examination was 5 RMB for each patient. If the patients wanted a prick test or blood examination to identify allergens, more than $200 \mathrm{RMB}$ was charged.

The average yearly income of a citizen in Beijing was 36,469 RMB in 2012 [28], which is about 3039 RMB per month and 100 RMB per day. The basic daily average medicine cost took $10 \%$ of the patient's income, and this can sometimes be an economic burden to patients.

\section{Discussion}

In this study, we conducted a one-year stationary outpatient's surveillance on AR, and during the study period, more than 1500 AR patients were invited to participate in our study. We combined the results from patient self-report questionnaires and specialist medical examination reports, to assess the disease burden of AR patients and severity of the patients. The basic daily medical cost of patients was also discussed in our research. In this survey, the patient-reported questionnaire corresponded to the actual situation of patients and provided a response from the patients. Specialist-examination report data on the characteristics of the patients corresponded to patients' responses. This was the first study to provide estimates of the disease burden of AR patients in Beijing or in China. The results of this study are novel for the following reasons. (1) All patients in our study were diagnosed by health professionals of the Department of Otolaryngology-Head and Neck Surgery of Beijing hospital, and all documentation was completed under the supervision of specialists, thereby avoiding over- or under-estimation, often related to self-reporting studies. (2) Both the patients' responses to a questionnaire and the specialists' examinations were taken into consideration. (3) The patient self-report questionnaire and specialist medical examination report were combined to assess the burden of disease, the severity, and the time and economic loss of AR patients.

Our study found that nearly half of the AR patients suffered from all four direct AR symptoms, $43.3 \%$ patients had three or more accompanied symptoms, $53.8 \%$ patients had sleep disturbances, $51.3 \%$ of patients had daily life limitations, and $38.0 \%$ of patients had altered work or learning impairment. AR imposed a substantial burden on patients regarding everyday life and work performance, which is consistent with other studies [11,23,24,29].

Although AR is not associated with severe morbidity and mortality, the condition exerts a significant burden on society due to its impact on health-related QOL (HR-QOL, health-related quality of life) [30]. In this study, we found that nearly half of the AR patients had comorbidities such as asthma 
and dermatitis. A survey conducted in Hungary showed that a significant proportion of patients have moderate or severe disease and persistent symptoms [31]. AR remains a significant health problem in Hungary, for the burden of symptoms, high rates of concomitant asthma, and the significant proportion of moderate or severe AR affecting general well-being [31]. Sleep-disordered breathing is also more common in patients with allergic diseases [32]. Results in our study indicated that all of the AR patients who consulted with specialists had moderate-to-severe severity AR. Compared with other studies [21,23], the ratio of patients with moderate-to-severe severity AR in our study was higher because we focused on outpatients in this research. Some patients with mild-severity AR thought AR did not have any effects in their lives, or the influence was minor and they did not realize the effects AR had on their lives. This interpretation of the results can be supported by a study conducted in France, where some AR patients were unaware of their pathology, few sought help from health professionals, and patients did not go to hospital. This group who neglected the effect of AR and did turn to doctor was therefore not included in the French study [29]. The differences found among the studies may also be the differences between questionnaire investigations and outpatient investigations.

In recent years, some studies have found that AR shares a pathological mechanism, and the conditions are different clinical manifestations of chronic inflammation of the upper and lower respiratory tracts [20,33-35]. Some researchers have proposed that severe chronic upper-airway disease arises when rhinitis is not controlled by adequate pharmacotherapy [10]. Nasal congestion is the most prominent symptom of AR, and it is associated with sleep-disordered breathing, a condition that can have a profound effect on mental health, including increased psychiatric disorders, depression, anxiety, and alcohol abuse [12]. For patients with AR, nasal congestion is a risk factor for apnea and snoring [32]. Allergic conjunctivitis is characterized by ocular itching, swelling, and discharge. Eye symptoms are present in $70 \%$ of people with seasonal AR and around $50 \%$ of those with perennial rhinitis [10].

The results from examinations by specialists in our study showed that AR can affect patients' noses, ears, throats, and eyes in various ways. Edema and paleness were the most common symptoms of patients' inferior turbinate mucosa, and most AR patients (about 76.7\%) suffered from two or more symptoms of their inferior turbinate mucosa. About half of the patients had invisible nasal middle turbinate. More than $50 \%$ of patients had an invisible nasal middle tract, and some patients had an invisible nasal middle tract and secretions inside. More than $50 \%$ of patients had a deviated nasal septum, and some patients had a moderate to severe deviated nasal septum. Many patients $(77.9 \%)$ had desquamation of the ear canal skin, and some patients had congestion or moisture in the eardrum. Most patients had throat congestion. Only 23.7\% patients had normal eyes, and most of the patients had congestion, edema, or watery eyes. These data also suggested that the symptoms of AR may have a negative impact on work capacity; however, it was not possible from this study to estimate the magnitude of that impact. The basic daily average medicine cost took $10 \%$ of the patient's income and brought economic burden to some patients. However, not all AR patients visiting the specialist asked for help, especially for those who had mild AR or patients who could not afford the economic cost, so there were much more costly conditions to treat, which can have a profound effect on AR cost in both direct and indirect ways. This study provides a preliminary approach to AR burden estimation. Several limitations remain. Reliance on outpatient visits over 12 months is one limitation. We were only able to use data from one hospital in Beijing as this was an initial study looking into the methodology and the usefulness of the approach. Secondly, because the catchment boundaries of hospitals in the central part of Beijing were not clearly defined, it was not possible to establish population characteristics within the catchment area. Likewise, possible differences in treatment-seeking behavior including the use of Traditional Chinese Medicine (TCM) could not be included in our study. The third potential limitation of the study was that rural-dwelling adults were not included. The fourth limitation was that we only considered the basic financial burden (the use of medicine and nasal examination costs in the hospital). Deeper investigation of the financial burdens for AR patients need to be comprehensively 
conducted. Further investigations of the above issues are necessary for improving disease management and patient quality of life.

\section{Conclusions}

In this research, the disease burden of patients with AR who consulted specialists as outpatients was studied. Self-report questionnaires from the AR patients and medical examination by specialists of otolaryngology were combined. The study found that all of the patients who consulted with specialists had moderate-to-severe AR, and had at least one troublesome symptom listed on the ARIA guidelines. AR imposed a burden on patients regarding everyday life limitations and work performance; and it can affect a patient's nose, ears, throat, and eyes in various ways. AR patients also experience time and economic loss for basic nasal examinations in the hospital. We hope that our study will lead to a deeper understanding of AR and improve disease management and patient quality of life.

Acknowledgments: The authors want to thank all the staff members at the Department of Otolaryngology-Head and Neck Surgery, Beijing Hospital, for their strong support of this study. We would like to thank the patients for their enthusiastic cooperation, which made this investigation possible. The present study was supported by the National Natural Science Foundation of China (No. 41371118; No. 41401101).

Author Contributions: Fengying Zhang conceived of the study, carried out the data analysis and the design of the study, and drafted the manuscript. Jin Xu carried out AR disease surveillance of outpatient in the hospital. Li Wang and Mark Rosenberg participated in the statistical analysis and language editing. Chengjing Nie, Wuyi Wang, and Thomas Krafft conceived of the study, and participated in its design and coordination, and helped to draft the manuscript. All authors read and approved the final manuscript.

Conflicts of Interest: All authors declare to have no conflict of interest to disclose in the context with this study.

\section{References}

1. Pawankar, R.; Canonica, G.; Holgate, S.; Lockey, R. Wao White Book on Allergy; World Allergy Organization: Milwaukee, WI, USA, 2011; pp. 1-216.

2. Bousquet, J.; Khaltaev, N.; Cruz, A.A.; Denburg, J.; Fokkens, W.J.; Togias, A.; Zuberbier, T.; Baena-Cagnani, C.E.; Canonica, G.W.; Van Weel, C.; et al. Allergic rhinitis and its impact on asthma (ARIA) 2008. Allergy 2008, 63, 8-160. [CrossRef] [PubMed]

3. Terreehorst, I.; Hak, E.; Oosting, A.J.; Tempels-Pavlica, Z.; de Monchy, J.G.; Bruijnzeel-Koomen, C.A.; Aalberse, R.C.; van Wijk, R.G. Evaluation of impermeable covers for bedding in patients with allergic rhinitis. N. Engl. J. Med. 2003, 349, 237-246. [CrossRef] [PubMed]

4. Meltzer, E.O. Allergic rhinitis: Burden of illness, quality of life, comorbidities, and control. Immunol. Allergy Clin. N. Am. 2016, 36, 235-248. [CrossRef] [PubMed]

5. Kakli, H.A.; Riley, T.D. Allergic rhinitis. Prim. Care Clin. Off. Pract. 2016, 43, 465-475. [CrossRef] [PubMed]

6. Wang, D.Y.; Ghoshal, A.G.; Muttalif, A.R.B.A.; Lin, H.-C.; Thanaviratananich, S.; Bagga, S.; Faruqi, R.; Sajjan, S.; Brnabic, A.J.M.; Dehle, F.C.; et al. Quality of life and economic burden of respiratory disease in Asia-Pacific-Asia-pacific burden of respiratory diseases study. Value Health Reg. Issues 2016, 9, 72-77. [CrossRef] [PubMed]

7. Hellgren, J.; Cervin, A.; Nordling, S.; Bergman, A.; Cardell, L.O. Allergic rhinitis and the common cold-high cost to society. Allergy 2010, 65, 776-783. [CrossRef] [PubMed]

8. Vuurman, E.; Van Veggel, L.; Uiterwijk, M.; Leutner, D.; O'Hanlon, J.F. Seasonal allergic rhinitis and antihistamine effects on children's learning. Ann. Allergy 1993, 71, 121. [CrossRef]

9. Crans Yoon, A.M.; Chiu, V.; Rana, J.S.; Sheikh, J. Association of allergic rhinitis, coronary heart disease, cerebrovascular disease, and all-cause mortality. Ann. Allergy Asthma Immunol. 2016, 117, 359-364. [CrossRef] [PubMed]

10. Greiner, A.N.; Hellings, P.W.; Rotiroti, G.; Scadding, G.K. Allergic rhinitis. Lancet 2011, 378, $2112-2122$. [CrossRef]

11. Bousquet, J.; Vignola, A.M.; Demoly, P. Links between rhinitis and asthma. Allergy 2003, 58, 691-706. [CrossRef] [PubMed]

12. Nathan, R.A. The burden of allergic rhinitis. Allergy Asthma Proc. 2007, 28, 3-9. [CrossRef] [PubMed] 
13. Skoner, D.P. Allergic rhinitis: Definition, epidemiology, pathophysiology, detection, and diagnosis. J. Allergy Clin. Immunol. 2001, 108, S2-S8. [CrossRef] [PubMed]

14. Brattmo, M.; Lindberg, S.; Wihl, J.A.; Petersson, G.; Malm, L. Allergic rhinitis and atopy in 18-year-old students. Am. J. Rhinol. 2002, 16, 323-327. [PubMed]

15. Villeneuve, P.J.; Doiron, M.S.; Stieb, D.; Dales, R.; Burnett, R.T.; Dugandzic, R. Is outdoor air pollution associated with physician visits for allergic rhinitis among the elderly in Toronto, Canada? Allergy 2006, 61, 750-758. [CrossRef] [PubMed]

16. Hansen, J.W.; Thomsen, S.F.; Nolte, H.; Backer, V. Rhinitis: A complication to asthma. Allergy 2010, 65, 883-888. [CrossRef] [PubMed]

17. Lancet, T. Allergic rhinitis: Common, costly, and neglected. Lancet 2008, 371, 2057. [CrossRef]

18. Hajat, S.; Haines, A.; Atkinson, R.W.; Bremner, S.A.; Anderson, H.R.; Emberlin, J. Association between air pollution and daily consultations with general practitioners for allergic rhinitis in London, United Kingdom. Am. J. Epidemiol. 2001, 153, 704-714. [CrossRef] [PubMed]

19. Zhang, F.; Wang, W.; Lv, J.; Krafft, T.; Xu, J. Time-series studies on air pollution and daily outpatient visits for allergic rhinitis in Beijing, China. Sci. Total Environ. 2011, 409, 2486-2492. [CrossRef] [PubMed]

20. Zhao, J.; Bai, J.; Shen, K.; Xiang, L.; Huang, S.; Chen, A.; Huang, Y.; Wang, J.; Ye, R. Self-reported prevalence of childhood allergic diseases in three cities of China: A multicenter study. BMC Public Health 2010, 10, 551. [CrossRef] [PubMed]

21. Schatz, M. A survey of the burden of allergic rhinitis in the USA. Allergy 2007, 62, 9-16. [CrossRef] [PubMed]

22. Meltzer, E.O.; Blaiss, M.S.; Derebery, M.J.; Mahr, T.A.; Gordon, B.R.; Sheth, K.K.; Simmons, A.L.; Wingertzahn, M.A.; Boyle, J.M. Burden of allergic rhinitis: Results from the pediatric allergies in America survey. J. Allergy Clin. Immunol. 2009, 124, S43. [CrossRef] [PubMed]

23. Canonica, G.; Bousquet, J.; Mullol, J.; Scadding, G.; Virchow, J. A survey of the burden of allergic rhinitis in Europe. Allergy 2007, 62, 17-25. [CrossRef] [PubMed]

24. Gupta, R.; Sheikh, A.; Strachan, D.; Anderson, H. Burden of allergic disease in the UK: Secondary analyses of national databases. Clin. Exp. Allergy 2004, 34, 520-526. [CrossRef] [PubMed]

25. Pereira, L.M.P.; Jackman, J.; Figaro, N.; Babootee, N.; Cudjoe, G.; Farrell, S.; Francis-Regis, C.; Garcia Henry, K.; Pandor, A.; Walters, T.; et al. Health burden of co-morbid asthma and allergic rhinitis in west Indian children. Allergol. Immunopathol. 2010, 38, 129-134. [CrossRef] [PubMed]

26. Zhang, F.; Krafft, T.; Zhang, D.; Xu, J.; Wang, W. The association between daily outpatient visits for allergic rhinitis and pollen levels in Beijing. Sci. Total Environ. 2012, 417-418, 39-44. [CrossRef] [PubMed]

27. Zhang, F.; Krafft, T.; Ye, B.; Zhang, F.; Zhang, J.; Luo, H.; Li, M.; Zhang, Y.; Zhou, L.; Xu, J.; et al. The lag effects and seasonal differences of air pollutants on allergic rhinitis in Beijing. Sci. Total Environ. 2013, 442, 172-176. [CrossRef] [PubMed]

28. China Statistics Press. Statistical Yearbook; Beijing Municipal Bureau of Statistics, NBS Survey Office: Beijing, China, 2013.

29. Demoly, P.; Didier, A.; Mathelier-Fusade, P.; Drouet, M.; David, M.; Bonnelye, G.; Blic, J.D.; Klossek, J.M. Physician and patient survey of allergic rhinitis in France: Perceptions on prevalence, severity of symptoms, care management and specific immunotherapy. Allergy 2008, 63, 1008-1014. [CrossRef] [PubMed]

30. Reed, S.D.; Lee, T.A.; McCrory, D.C. The economic burden of allergic rhinitis. Pharmacoeconomics 2004, 22, 345-361. [CrossRef] [PubMed]

31. Szilasi, M.; Gálffy, G.; Fónay, K.; Márk, Z.; Rónai, Z.; Szalai, Z.; Szilasi, M.E.; Budai, M.; Müller, V.; Somfay, A. A survey of the burden of allergic rhinitis in hungary from a specialist's perspective. Multidiscipl. Respir. Med. 2012, 7, 1-6. [CrossRef] [PubMed]

32. Koinis-Mitchell, D.; Craig, T.; Esteban, C.A.; Klein, R.B. Sleep and allergic disease: A summary of the literature and future directions for research. J. Allergy Clin. Immunol. 2012, 130, 1275-1281. [CrossRef] [PubMed]

33. Maziak, W.; Behrens, T.; Brasky, T.M.; Duhme, H.; Rzehak, P.; Weiland, S.K.; Keil, U. Are asthma and allergies in children and adolescents increasing? Results from isaac phase I and phase III surveys in Münster, Germany. Allergy 2003, 58, 572-579. [CrossRef] [PubMed] 
34. Simons, F.E.R. What's in a name? The allergic rhinitis-asthma connection. Clin. Exp. Allergy Rev. 2003, 3, 9-17. [CrossRef]

35. Simons, F. Allergic rhinobronchitis: The asthma-allergic rhinitis link. J. Allergy Clin. Immunol. 1999, 104, 534-540. [CrossRef]

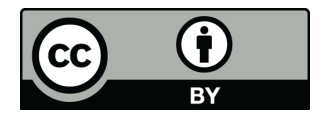

(C) 2017 by the authors. Licensee MDPI, Basel, Switzerland. This article is an open access article distributed under the terms and conditions of the Creative Commons Attribution (CC BY) license (http:/ / creativecommons.org/licenses/by/4.0/). 